\title{
Nucleotide sequence of a repetitive element isolated from Leptospira interrogans serovar hardjo type hardjo-bovis
}

\author{
M. J. WoodWARD* and G. J. SulLIVAN \\ Molecular Genetics Unit, Central Veterinary Laboratory, New Haw, Weybridge, Surrey KT15 3NB, UK
}

(Received 9 October 1990; revised 10 January 1991; accepted 11 February 1991)

\begin{abstract}
A repetitive element from the genome of Leptospira interrogans serovar hardjo type hardjo-bovis ('L. hardjo-bovis') was identified, cloned and sequenced. Similar sequences were shown by hybridization to be encoded by a further eight of 32 other leptospiral serovars tested. An undefined number of repetitive elements were located in the L. hardjo-bovis genome; sequence degeneracy of the elements was observed and no significant open reading frames were identified within the AT-rich $(60 \%) 1467$ bp repetitive element. The termini encoded a GC-rich 8 bp repeat motif and two variants showed rearrangements centred on these motifs. The nucleotide sequences of the chromosomal regions flanking the repetitive elements were determined but showed no similarities, with one exception which had a GAAC repeat directly adjacent to both termini. Similar hybridization patterns were shown by Southern transfers of $L$. hardjo-bovis total genomic digests probed with the repetitive element. Oligonucleotide primer pairs designed from sequences internal to the repetitive element and adjacent chromosomal regions were used in polymerase chain reaction experiments. With one primer pair all $L$. hardjo-bovis isolates, but no other serovar, gave identical amplified products. Evidence that the repetitive element may have derived from an acquired insertion sequence that is now inactive and chromosomally fixed is discussed.
\end{abstract}

\section{Introduction}

Leptospirosis is a zoonotic disease that affects cattle, swine, rodents and domestic pets (Ellis, 1986). Human cases are often a result of occupational or accidental contact with infected animals or due to ingestion of water contaminated with their urine (Lecour et al., 1989; Thiermann, 1984). The genus Leptospira comprises three species; L. interrogans isolates are recognized as pathogens whereas L. biflexa and L. parva are apparently freeliving saprophytes (Johnson \& Faine, 1984). The species L. interrogans contains over 170 serovars organized into 19 serogroups, differentiation being dependent upon microscopic agglutination tests and cross-absorption with group- and serovar-specific hyperimmune serum (Cole, 1984). Currently the detection and characterization of leptospires are done by culture isolation and serology, which are both time-consuming and difficult to perform. L. interrogans serovar hardjo type hardjo-bovis ('L.hardjo-bovis')is believed to be the major cause of milk

Abbreviation: PCR, polymerase chain reaction.

The nucleotide sequence data reported in this paper (consensus sequence) have been submitted to GenBank and have been assigned the accession number M57713. drop syndrome and abortion in cattle in the UK and Australasia (Chappel et al., 1989). Ellis et al. (1982), however, reported the high incidence of $L$. interrogans serovar hardjo type hardjo-prajitno ('L. hardjo-prajitno') in aborted foetuses from random sampling and from herds with abortion problems in Ireland. Other serogroups, notably Canicola, Grippotyphosa and Sejroe, are found frequently in domestic animals and may have a pathogenic effect in cattle (T. W. A. Little \& N. M. A. Palmer, personal communication). Restriction endonuclease analysis of bacterial DNA and DNA hybridization studies have been used extensively to establish epidemiological relationships between isolates and their hosts, as well as attempting to determine genetic relatedness amongst leptospires (Marshall et al., 1981; Robinson et al., 1982; Terpstra et al., 1986; Hata et al., 1988; Van Eys et al., 1988; Silbreck \& Davies, 1989; Nielsen et al., 1989). Recently, detection of leptospires has been attempted using gene probes (Zuerner \& Bolin, 1988 ) and the polymerase chain reaction (PCR) (Van Eys et al., 1989). It was our intention to develop gene probes/PCR reagents which could be applied directly to clinical samples such as urine or material from aborted foetuses and which would not only detect but also differentiate between important serovars. 


\section{Methods}

Bacterial strains. All leptospires were from the Central Veterinary Laboratory culture collection; they were grown on EMJH medium (Ellis et al., 1982) and stocks were stored as freeze-dried samples. DNA of $L$. hardjo-bovis strain B215 was used for cloning experiments. Competent cells of Escherichia coli K12 strain DH5a (Life Technologies) were used as recipients in transformation experiments.

Genetic methods. Total genomic DNA was extracted from Leptospira species using the gentle lysis method of Zainuddin \& Dale (1989). Genomic DNA ( $50 \mu \mathrm{g}$ in $500 \mu \mathrm{l} \mathrm{TE})$ was sheared by repeated forcing through a 21 gauge needle using a $1 \mathrm{ml}$ syringe. Samples $(10 \mu 1)$ were taken at intervals during shearing and run through agarose gel, stained with ethidium bromide and visualized by UV transillumination (Maniatis et al., 1982). After about 12 passages the DNA was sheared to predominantly between 5 and $10 \mathrm{~kb}$ in size. A method based on that described by Ohtsubo \& Ohtsubo (1977) was used to identify repeat DNA sequences. The sheared DNA, approximately $50 \mu \mathrm{g}$ in $500 \mu \mathrm{l} \mathrm{TE}$ in an Eppendorf tube $(1.5 \mu \mathrm{l})$, was placed in a waterbath and heated to $95^{\circ} \mathrm{C}$ for $5 \mathrm{~min}$. The temperature of the waterbath was reduced gradually to $37^{\circ} \mathrm{C}$ over a $30 \mathrm{~min}$ period by addition of ice. Buffer $(50 \mu 1 \times 10$ concentration) and 2 units $\mathrm{S} 1$ nuclease (Life Technologies) were added to the sheared DNA and digestion of single stranded DNA continued at $37^{\circ} \mathrm{C}$ for up to $20 \mathrm{~min}$. Samples of reaction mixture $(100 \mu \mathrm{l})$ were taken at $5 \mathrm{~min}$ intervals, extracted twice with an equal volume of phenol/chloroform $(1: 1, \mathrm{v} / \mathrm{v})$ and ethanol-precipitated after addition of sodium acetate to a final concentration of $300 \mathrm{mM}$ (Maniatis et al., 1982). After centrifugation $\left(13000 \mathrm{~g}, 4^{\circ} \mathrm{C}, 30 \mathrm{~min}\right)$, the DNA pellets were washed with $70 \%(\mathrm{v} / \mathrm{v})$ ice-cold ethanol, air-dried, dissolved in TE $(10 \mu \mathrm{l})$ and samples $(5 \mu \mathrm{l})$ examined by agarose gel electrophoresis. DNA was extracted from agarose gels by freezing to $-70^{\circ} \mathrm{C}$ small blocks of agarose containing desired DNA bands placed within Costar tubes (Northumbrian Biologicals). The frozen tubes were centrifuged at $13000 \mathrm{~g}$ at room temperature for $10 \mathrm{~min}$. The eluate containing DNA was extracted with an equal volume of phenol/chloroform $(1: 1, \mathrm{v} / \mathrm{v})$ and the DNA precipitated by ethanol as described above. Infilling using DNA polymerase Klenow fraction V (Life Technologies) followed the manufacturer's recommendations. The use of restriction endonucleases and T4 ligase for digestion and ligation, respectively, of DNA species followed the methods of Sambrook et al., (1989) and the manufacturer's (Life Technologies) recommendations. The plasmid pUC18 (Life Technologies) was used as cloning vector and for transformation, with selection of transformants of competent $E$. coli $\mathrm{DH} 5 \alpha$ being made on LB agar supplemented with ampicillin $\left(100 \mu \mathrm{g} \mathrm{ml}^{-1}\right)$ and $\mathrm{X} \cdot \mathrm{gal}\left(40 \mu \mathrm{g} \mathrm{ml}^{-1}\right)$, in accordance with the supplier's recommendations.

Hybridization. Colonies for hybridization grown on LB agar supplemented with ampicillin $\left(100 \mu \mathrm{g} \mathrm{ml} \mathrm{m}^{-1}\right)$ were replicated onto Hybond-N (Amersham) nylon filters followed by lysis and fixation of the released DNA by UV transillumination in accordance with the manufacturer's recommendations. Total genomic DNA $(4 \mu \mathrm{g})$ digested overnight at $37^{\circ} \mathrm{C}$ with $50 \mathrm{U} \mathrm{BamHI}$ and subjected to electrophoresis $\left(1 \%\right.$, w/v, agarose, $24 \mathrm{~cm}$ path, $80 \mathrm{~V}$ constant voltage, $\left.16 \mathrm{~h}, 4^{\circ} \mathrm{C}\right)$ was transferred to Hybond-N (Amersham) nylon filters using the method of Southern as described by Maniatis et al., (1982). Filters were prehybridized for $2 \mathrm{~h}$ at $42^{\circ} \mathrm{C}$ in $50 \%(\mathrm{v} / \mathrm{v})$ formamide, $6 \times \operatorname{SSC}(1 \times$ SSC is $0.15 \mathrm{M}-\mathrm{NaCl}, 0.015 \mathrm{M}$-sodium citrate, pH 7), $5 \times$ Denhardt's solution $(1 \times$ Denhardt's solution is $0.02 \%, \mathrm{w} / \mathrm{v}$, bovine serum albumin pentax fraction $\mathrm{V} ; 0.02$, w/v, Ficoll $M_{\mathrm{r}} 400000 ; 0.02 \%, \mathrm{w} / \mathrm{v}$, polyvinylpyrrolidone $M_{\mathrm{r}} 360000$ ), $100 \mathrm{~mm}$-dithiothreitol and sonicated denatured salmon sperm DNA (10 $\mu \mathrm{g}$ per ml solution) contained within borosilicate glass roller bottles inside a hybridization oven (HYBAID). Probes were prepared by cutting the desired DNA band from $1.2 \%$
Nusieve agarose (FMC Biochemicals) gels and denaturing the DNA in $4 \times$ volumes of distilled $\mathrm{H}_{2} \mathrm{O}$ by heating to $94^{\circ} \mathrm{C}$ for 5 min. Samples $(10 \mu \mathrm{l})$ containing up to $50 \mathrm{ng}$ DNA were labelled with $\left[{ }^{32} \mathrm{P}\right] \mathrm{dCTP}$ to a specific activity approaching $1 \times 10^{9}$ c.p.m. $\mu \mathrm{g}^{-1}$ by random hexanucleotide priming (Amersham) as described by Feinberg \& Vogelstein (1983). The labelled probe reaction mixture was denatured at $94{ }^{\circ} \mathrm{C}$ for $2 \mathrm{~min}$ and added to filters along with fresh hybridization solution $(5 \mathrm{ml}$ per $100 \mathrm{~cm}^{2}$ filter). Hybridization continued for $16 \mathrm{~h}$ at $42^{\circ} \mathrm{C}$. Posthybridization washes were sequentially with $2 \times$ SSC, $2 \times$ SSC containing $0.1 \% \mathrm{SDS}$, and $0.2 \times \mathrm{SSC}$ containing $0.1 \% \mathrm{SDS}$, all at $65^{\circ} \mathrm{C}$ for $30 \mathrm{~min}$ each. Filters were air-dried and exposed to X-ray film (Fuji$\mathrm{RX}$ ) for up to $16 \mathrm{~h}$.

DNA nucleotide sequencing. Double stranded DNA sequencing was done throughout using Sequenase version 2.0 and in accordance with the manufacturer's (Cambridge Life Sciences) recommendations. Primers (24-mers) were synthesized on an ABI PCR-mate following the maker's recommendations. Both strands were sequenced according to the schedule shown in Fig. 2. The sequences obtained were compiled and analysed using STADEN plus version 5.0 software (Amersham).

PCR. The methods of Saiki et al. (1985) were followed. Primers were synthesized as described above and conditions for each pair of primers were determined empirically by titrating $\mathrm{Mg}^{2+}$ concentration and temperature for each cycle. Taq polymerase was supplied by PerkinElmer Cetus (Amplitaq) and dNTPs were supplied by Boehringer. Initial PCR experiments were carried out on purified DNA. Routine sample preparation was as follows. One millilitre of Leptospira culture was centrifuged $(13000 \mathrm{~g}, 2 \mathrm{~min})$, and the pellet was resuspended in $50 \mu \mathrm{l}$ distilled $\mathrm{H}_{2} \mathrm{O}$ and thoroughly vortexed in buffered phenol (Maniatis et al., 1982). The lysate was centrifuged $(12000 \mathrm{~g}, 2 \mathrm{~min}$ ) and $1-5 \mu \mathrm{l}$ of aqueous phase and serial dilutions were transferred to the PCR reaction tubes. A HYBAID thermal cycler was used in all experiments. When using primers $3 \mathrm{~A}\left(5^{\prime}\right.$ CCGGAAAGAAGGGGCGCCAT $3^{\prime}$ ) and 3B (5' CGATTTAGAAGGACTTGCACAC $3^{\prime}$ ), oligonucleotides were used at a concentration of $50 \mathrm{pM}$ in Saiki buffer containing $6 \mathrm{mM}-\mathrm{MgCl}_{2}$. Twenty-five cycles of $95^{\circ} \mathrm{C}$ for $2 \mathrm{~min}, 61^{\circ} \mathrm{C}$ for $3 \mathrm{~min}$ and $72{ }^{\circ} \mathrm{C}$ for $2 \mathrm{~min}$ were used.

\section{Results}

\section{Cloning the repetitive DNA element of $L$. hardjo-bovis}

The sensitivity of gene probes and PCR may be enhanced if the test organism harbours multiple copies of the target sequence, such as rRNA genes or repeat motifs. A search for repeated sequences within the $L$. hardjo-bovis genome using the methods of Ohtsubo \& Ohtsubo (1977) was done. Essentially, total genomic DNA from $L$. hardjo-bovis strain B215 was mechanically sheared to give fragments of average sizes between $5 \mathrm{~kb}$ and $10 \mathrm{~kb}$, heated to $95^{\circ} \mathrm{C}$ for $5 \mathrm{~min}$ to denature the DNA and allowed to cool slowly to room temperature for $30 \mathrm{~min}$. The annealed DNA was treated by $\mathrm{S} 1$ digestion to remove single-stranded DNA, run through an agarose (1\%) gel and the predominant DNA bands visualized by UV transillumination after ethidium bromide staining. A diffuse band of about $1.5 \mathrm{~kb}$ was visible (Fig. 1). Similar experiments with $L$. hardjo-prajitno gave no predominant bands. A gel slice containing the DNA was 


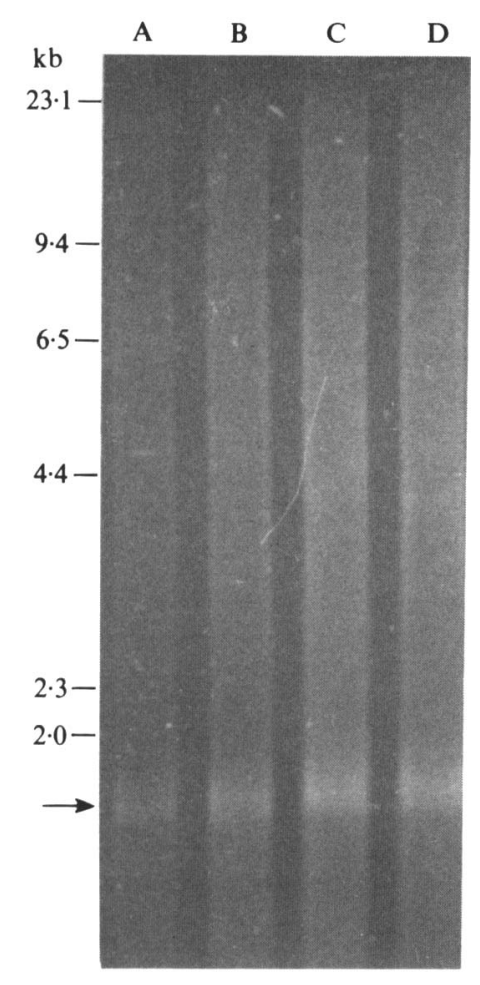

Fig. 1. Total genomic DNA from L. hardjo-bovis was sheared, denatured, annealed and treated with $S 1$ nuclease to remove singlestranded DNA. Samples of reactions using DNA from strains B215 (lane A), 87/12/1 (lane B), 87/26/469 (lane C) and 88/23A/42 (lane D) are shown after electrophoresis through $1 \%(\mathrm{w} / \mathrm{v})$ agarose. The arrow indicates the position of the repetitive element and relative mobilities of $\lambda$ HindIII size markers are indicated.

excised, and the DNA was recovered by freeze-thawing and purified by phenol/chloroform extraction and ethanol precipitation. Recessed strands of the isolated DNA were infilled using Klenow DNA polymerase and ligated to SmaI-cut pUC18 vector. The ligation mixture was used to transform E. coli DH $5 \alpha$ and selection made for ampicillin resistance. Twelve white transformants were purified, plasmids extracted and each was shown by $K p n \mathrm{I} /$ Bam HI double digestion to have an insert of about $1.5 \mathrm{~kb} ; \mathrm{KpnI}$ and BamHI were chosen because these restriction enzymes have recognition sites immediately flanking the SmaI site used for cloning. The $1.5 \mathrm{~kb}$ $K p n$ / BamHI fragments from four of these digests were purified from low-gelling-temperature agarose gels and used separately as hybridization probes against Southern transfers of preparations similar to those shown in Fig. 1. In each case a strong hybridization signal was observed corresponding to the diffuse DNA bands at about $1.5 \mathrm{~kb}$ (data not shown).

At the time of doing these experiments, Zuerner \& Bolin (1988) published the cloning and restriction endonuclease mapping of a $1.4 \mathrm{~kb}$ repetitive element isolated from the $L$. hardjo-bovis genome. In their experiments, $L$. hardjo-bovis genomic DNA was digested with numerous restriction endonucleases; digestion with NarI gave a predominant $1.4 \mathrm{~kb}$ fragment which was cloned into the $A c c$ I site of pUC8. One recombinant made in this work, designated pVW 300 , was examined further by restriction endonuclease digestion and a map (Fig. 2) broadly similar to that described by Zuerner \& Bolin (1988) established. The insert in pVW300 differed in that the locations of the ClaI and XmnI sites were identical (common recognition sequence) and the location of the $N r u$ I site was $100 \mathrm{bp}$ not $300 \mathrm{bp}$ from the outside end of the repetitive element. Assuming the elements described in this work and by Zuerner \& Bolin (1988) were homologous, the variation of restriction maps indicated sequence polymorphism.

\section{Distribution of sequence homologous with the repetitive element within leptospires and apparent constant chromosomal location in L. hardjo-bovis}

DNA was extracted from single isolates of 32 serovars representative of 15 serogroups and used as target in dotblot experiments with the repetitive element isolated as a $K p n \mathrm{I} /$ BamHI $1.5 \mathrm{~kb}$ fragment from pVW300 as probe. Hybridizing serovars were javanica and poi (serogroup Javanica), zanoni (serogroup Pyrogenes), balcanica, hardjo-bovis, istrica, saxkoebing and sejroe (serogroup Sejroe) and tarassovi (serogroup Tarassovi). Serovars which did not hybridize were australis, bratislava and muenchen (serogroup Australis), ballum (serogroup Ballum), bataviae (serogroup Bataviae), celledoni (serogroup Celledoni), cynopteri (serogroup Cynopteri), grippotyphosa (serogroup Grippotyphosa), hebdomadis (serogroup Hebdomadis), icterohaemorrhagiae $\mathrm{Vi}^{+}$and $\mathrm{Vi}^{-}$ (serogroup Icterohaemorrhagiae), mini (serogroup Mini), panama (serogroup Panama), mozdoc, pomona and proechimys (serogroup Pomona), pyrogenes (serogroup Pyrogenes), hardjo-prajitno, medanensis, recreo, ricardi, roumanica, trinidad and wolffi (serogroup Sejroe).

Zuerner \& Bolin (1988) suggested that there were about 40 copies of the repetitive element in the L. hardjobovis genome. To determine whether this was true of the isolates in the Central Veterinary Laboratory collection, the repetitive element was used to probe Southern transfers of total genomic BamHI digests. The restriction endonuclease $B a m H I$ was used because the repetitive element lacks a recognition site for this enzyme. An example of the results obtained is shown in Fig. 3. With $L$. hardjo-bovis, the number of discrete hybridizing bands was difficult to estimate. In all, 30 isolates of $L$. hardjobovis were confirmed by dot-blot hybridization to encode the repetitive element; 12 of these, from the UK (8), Ireland (2) and Zimbabwe (2), were analysed by 


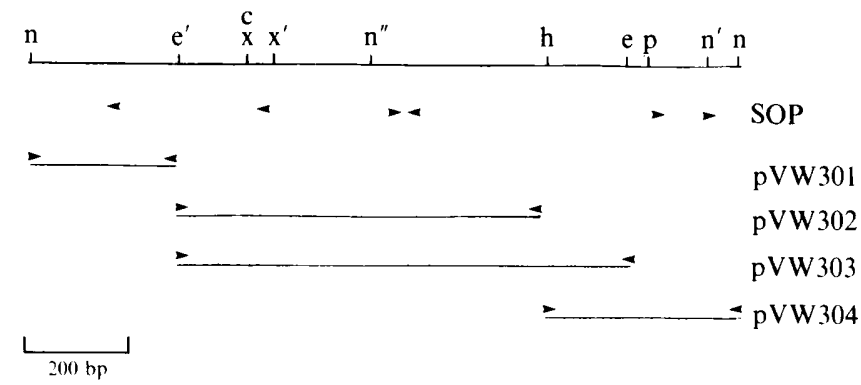

Fig. 2. The map of the repetitive element as deduced by restriction endonuclease mapping and confirmed by sequencing. c, ClaI; e, EcoRI ; e', EcoRV; h, HindIII; n, NarI; n', NruI ; n" NdeI; p, PvuII; , $X m n I ; x^{\prime}, X b a I$. Subclones were constructed either by excision of specific fragments and recloning in pUC18 cut with compatible cohesive ends (EcoRV/HindIII, pVW302;EcoRV/EcoRI, pVW303), or by deleting DNA between restriction endonuclease recognition sites located internal to the insert and compatible sites of the multiple cloning site (EcoRV/SmaI, pVW301; HindIII/HindIII, pVW304). Sequencing made use of forward and reverse pUC primers (indicated by arrowheads at the ends of each subclone) and synthetic oligonucleotide primers (SOP) made by ABI PCR mate which were homologous to deduced sequences from initial sequencing reactions (indicated by arrows).

Southern hybridization of genomic digests and shown to have similar hybridization patterns although, as can be seen from Fig. 3, interpretation was subjective. $L$. saxkoebing is serologically similar to $L$. hardjo-bovis and a potential cause for concern for misdiagnosis by serological testing. It has been isolated from fox, badger, woodmouse and cat but never from cattie in the UK (N. M. A. Palmer \& J. Redstone, personal communication). Four isolates of $L$. saxkoebing were also tested by Southern hybridization and shown to harbour about 12 copies of the repetitive element. Again, the hybridization patterns from each isolate were similar. Here was evidence of a possible method, if refined further, for differentiation between serovars and an indication of the conservation of the repetitive element in fixed chromosomal locations.

\section{Sequence analysis of the repetitive element}

It was considered unlikely that the method for cloning the repetitive element used in this work would give a fulllength sequence, because of probable infidelity of S1 nuclease digestion. Furthermore, it was considered important not only to establish the true ends of the repetitive element but also to determine if commonality of sequences existed between chromosomal regions adjacent to the repetitive elements. Therefore, repetitive elements with flanking chromosomal regions were cloned for use in sequencing experiments. To do this, total genomic DNA of $L$. hardjo-bovis was digested to

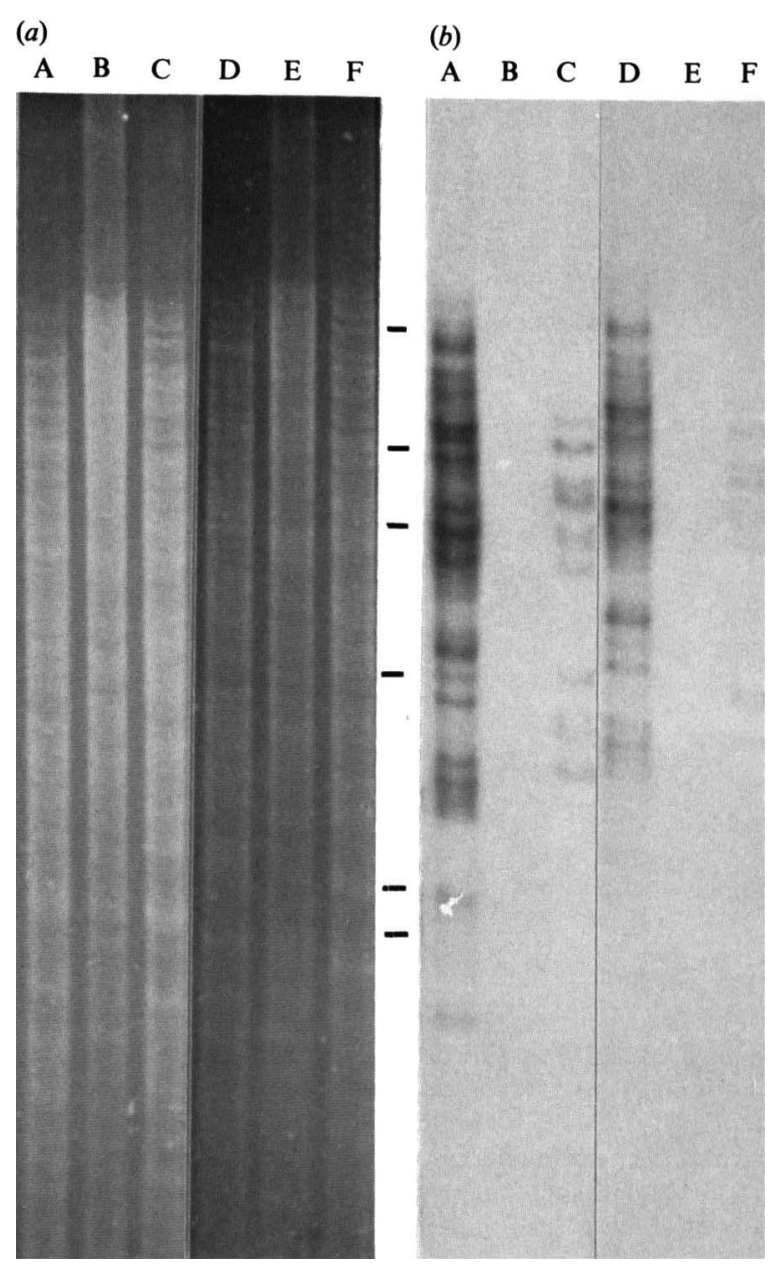

Fig. 3. (a) Total genomic DNA from L. hardjo-bovis B215 (lane A) and 87/12/1 (lane D), L. hardjo-prajitno 1 (lane B) and Ellis 6 (lane E), and $L$. saxkoebing 1 (lane $\mathrm{C}$ ) and 2 (lane $\mathrm{F}$ ) digested to completion with Bam $\mathrm{HI}$ is shown after eiectrophoresis through $1 \%(w / v)$ agarose. The positions of $\lambda$ HindIII size markers are indicated (see Fig. 1 for sizes in kb). (b) Southern transfer of the DNA shown in $(a)$ hybridized with the repetitive element isolated as a $1.5 \mathrm{~kb} \mathrm{KpnI} / \mathrm{BamHI}$ fragment from pVW300.

completion with BamHI, ligated with dephosphorylated BamHI-cut pUC18 and used to transform E. coli DH5 $\alpha$. Transformants were hybridized with the KpnI/BamHI $1.5 \mathrm{~kb}$ insert from pVW 300 in colony hybridization experiments to detect recombinants harbouring the repetitive element. Recombinant plasmids from 20 transformants (pVW311-330) shown to encode the repetitive element were extracted, digested with BamHI and demonstrated by agarose gel electrophoresis to have inserts ranging from $5 \mathrm{~kb}$ to $13 \mathrm{~kb}$ in size.

A series of subclones of pVW 300 were made in $\mathrm{pUC} 18$ (see Fig. 2). Use was made of pUC forward and reverse primers for initial sequencing whilst oligomer primers 




Fig. 4. Nucleotide sequence of the L. hardjo-bovis repetitive element from clone $\mathrm{pVW} 300$. The presumptive termini were determined by sequencing across the repetitive element/chromosome junction of 20 genomic fragments encoding the element ( $\mathrm{pVW} 311-300$ ); the termini were determined from the consensus sequence. 


\section{(a) Consensus}

pVW 324

$\mathrm{pVW} 319 / 321$

pVW316

pVW317

(b) Consensus

pVW 321

pVW315

pVW 323
50

CGCATCTAAC

-・

- $\mathrm{G}$

-

A

A

A

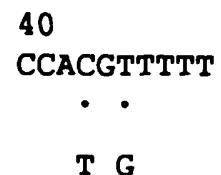

T G

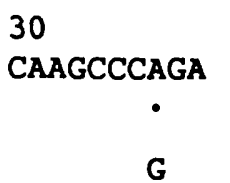

G

1440

AAAAAAGATT
1430

AAAATATGCG

\section{•}

•

Fig. 5. The consensus sequences of the left $(a)$ and right $(b)$ termini of the repetitive element, showing which bases differed in particular cloned copies of the element.

were synthesized and used in reactions to complete sequencing of both strands (Fig. 2). A pair of oligomer primers homologous to sequence about $100 \mathrm{bp}$ in from the repetitive element termini were synthesized (referred to as outward primers) and used to determine the repetitive element termini-chromosome junctions in sequencing experiments using several of the pVW311330 plasmids as templates. A consensus sequence of 1467 bp for the repetitive element was established (Fig. 4) but there was sequence variation at the termini of individual repetitive elements as demonstrated by sequence comparison when using outward primers (Fig. 5). To test the extent of sequence variation, several internal synthetic oligomer primers were used in reactions to sequence the repetitive elements of plasmids pVW311-330 (data not shown). This was an incomplete survey but it demonstrated that base changes occurred about once every $70 \mathrm{bp}$ and also indicated that there were no specific hot-spots at which variation occurred.

The repetitive element was AT-rich $(60 \%)$, as were the flanking chromosomal regions. No large open reading frame within the repetitive element was identified; indeed the largest open reading frame was $291 \mathrm{bp}$. As for potential for secondary structure, no large repeat motifs were identified. However, an 8 bp motif, GGCGCCCC, was located at both termini (12-19 and 1461-1454). The motif, which contains the recognition sequence for NarI used by Zuerner \& Bolin (1988) for identification and subsequent cloning of the repetitive element, is unusually GC-rich; there are very few sites for other restriction endonucleases with GC-rich recognition sequences. Examination of the terminal sequences derived from pVW321 and pVW324 with the consensus sequence revealed a right end for left end substitution centred on the GC-rich motif on the one hand and a reiteration of the GC-rich motif with a loss of the terminal $8 \mathrm{bp}$ on the other hand. Flanking chromosomal regions, of about $250 \mathrm{bp}$ either side of the repetitive element (data not shown), were analysed for any significant commonality but none was observed. One repetitive element (pVW312), however, shared a 4 bp (GAAC) inverted repeat immediately flanking the element. A search of the GenBank and EMBL databases revealed no significant homology with any other sequences except for poly(A) and poly $(\mathrm{T})$ tracts found in many eukaryotic sequences.

\section{Evidence for conservation of chromosomal location of repetitive elements}

The evidence so far indicated that the repetitive elements in L. hardjo-bovis (and presumably L. saxkoebing) were degenerate sequences and possibly fixed in 


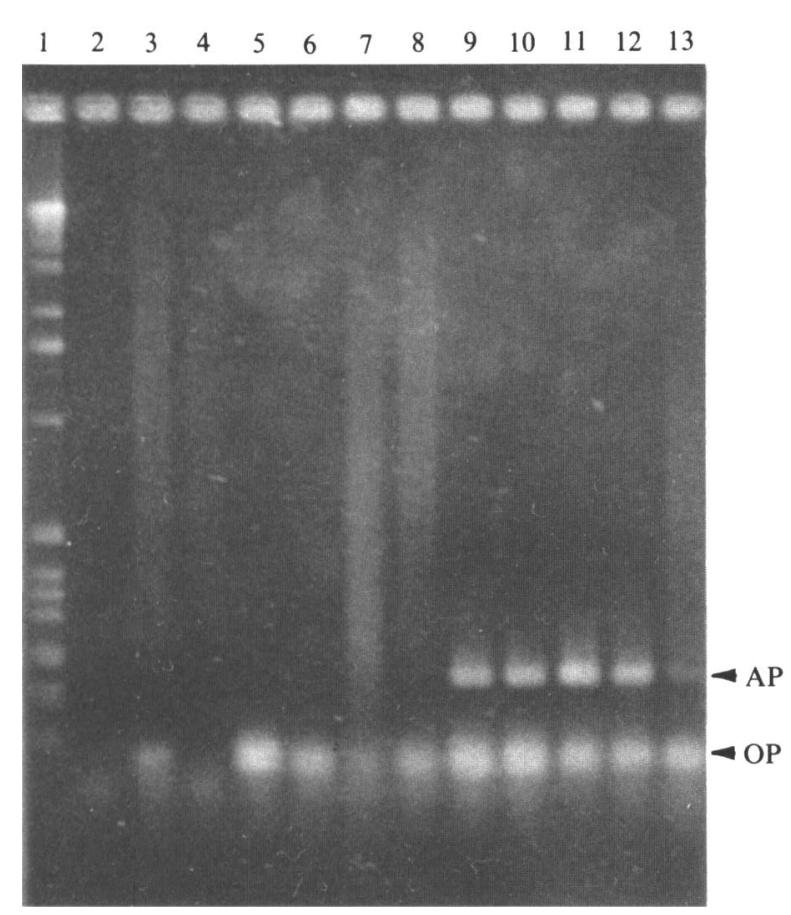

Fig. 6. PCR reactions using primer pair $3 \mathrm{~A} / 3 \mathrm{~B}$ of cell lysate samples $(1 \mu$ l) from $L$. hardjo-bovis strains B215 (lane 13), Ellis 2-Northern Ireland (lane 12), 87/12/1 Zimbabwe (lane 11), 87/32.Hfr9-UK (lane 10), 88/23/136-UK (lane 9), L. saxkoebing strains 766V1 (lane 8) and $776 \mathrm{~V} 2$ (lane 7), and L. hardjo-prajitno strains 1 - UK (lane 6), 2-UK (lane 5), Ellis 6-Northern Ireland (lane 4) and Ellis 7-Northern Ireland (lane 3). Lane 2 is a negative control and lane 1 contains size markers (1 kilobase ladder; Life Technologies). The amplified product $(187 \mathrm{bp})$ is labelled AP whilst excess oligonucleotide primers and primer dimers are labelled $O P$.

specific chromosomal locations. To test this latter hypothesis, pairs of synthetic oligomer primers were made homologous to internal regions of the repetitive element on the one hand and homologous to flanking chromosomal regions on the other. These pairs of primers were used in PCR experiments with 30 different $L$. hardjo-bovis isolates. In principle, if the sequences complementary to the primers were juxtaposed in the test isolates, then a discrete amplified product of the desired size would be observed. One primer pair was designed using sequences derived from pVW324. Primer $3 A\left(5^{\prime}\right.$ CCGGAAAGAAGGGGCGCCAT 3') was homologous with the variant left end of the repetitive element whilst primer $3 \mathrm{~B}$ ( $5^{\prime}$ CGATTTAGAAGGACTTGCACAC $3^{\prime}$ ) was homologous to flanking chromosomal sequence and the predicted size of amplified product was $187 \mathrm{bp}$. All $30 \mathrm{~L}$. hardjo-bovis isolates collected from the UK, Ireland and Zimbabwe were tested and gave the predicted amplified product. Furthermore, in Southern hybridization experiments, the amplified products were shown to be homologous with the PCR product amplified using pVW324 as template. The primers $3 \mathrm{~A}$ and 3B did not give amplified product with $L$. hardjoprajitno (8 isolates) or L. saxkoebing (4 isolates) or with single isolates representative of 29 other serovars. An example of the results is shown in Fig 6.

\section{Discussion}

The repetitive element of $L$. hardjo-bovis described in this work is most probably the same as that described by Zuerner \& Bolin (1988). There are differences between the restriction endonuclease maps but this is most probably explained by the considerable degeneracy of sequences amongst the many copies of the element encoded by the host cell. The element has a limited distribution within leptospires, being found in two serovars of the Javanica serogroup, one of two serovars tested of the Pyrogenes serogroup and five of twelve serovars tested belonging to the Sejroe serogroup. Although this survey is limited, it may indicate relatedness if, for example, the element evolved from a progenitor gene within an ancient leptospire and, therefore, serovars harbouring the element are clonally derived. Alternatively, a more likely explanation is that the element is a classic IS element or transposon (Calos \& Miller, 1980) which has infected the leptospiral gene pool. Infection by such an element may be historically recent and random and, thus, may not indicate clonal relatedness. The evidence to suggest that the element is (or was) an IS element comes from sequence analysis. An 8 bp GC-rich sequence was found repeated about $12 \mathrm{bp}$ in from the apparent ends of the element and these could be target sequences for transposition; repeated termini are a feature of mobile genetic elements (Calos \& Miller, 1980). The fact that novel forms of the termini were identified (pVW321 and pVW324) suggests that these may have arisen by incorrect crossing-over between adjacent termini, perhaps brought together during transposition. One repetitive element was flanked by a 4 bp repeat, a feature common to many mobile genetic elements such as Tn3 (Hefron, 1983) and Tn10 (Kleckner, 1979), which have 5 bp and 9 bp repeats, respectively. No genetic systems are yet available in leptospiral species to test whether these repetitive elements are mobile. Certainly, there was no evidence of spontaneous genetic rearrangements of any of the cloned repetitive elements in $E$. coli; but $E$. coli is probably a non-permissive host.

The sequences of the repetitive elements were highly degenerate. Accumulation of many mutations may indicate ancient acquisition of the elements and explain the lack of a significant open reading frame to encode a transposase or any other gene function. Also, prelimi- 
nary data from PCR experiments suggest that the elements may be fixed in relation to flanking chromosomal sequences. Indeed, the same repetitive element/ chromosomal alignment in isolates of $L$. hardjo-bovis from such geographically separated regions as the UK and Central Africa were observed. It is tempting to speculate, therefore, that $L$. hardjo-bovis is derived clonally from an ancestral leptospire in which the repetitive element, historically as a transposable element, entered the genome. However, the evidence to support this is as yet very tenuous. A significant feature of this repetitive element is the high copy number in $L$. hardjo-bovis and also $L$. saxkoebing. It is generally assumed that saturating numbers of IS elements and transposons are potentially lethal to a cell and selfregulation mechanisms to repress transposition have evolved (Berg, 1980). It is possible that a derepressed burst of transposition saturated the chromosome with many copies of the element and gave rise to the $L$. hardjobovis clone. Alternatively, these repetitive elements may not be is elements or transposons, degenerate or otherwise, but rather function as target sequences for intracellularization during transformation, or perhaps encode some cryptic activity or act as recombinational hot-spots. This may explain how recognized restriction endonuclease polymorphs of $L$. hardjo-bovis have arisen (Thiermann et al., 1986). Alternatively, it is possible that one or more copies of the element may still possess an active transposase which may act in trans to mobilize elements and thus generate restriction endonuclease polymorphisms.

Nielsen et al. (1989) used cross-hybridization of total genomic DNA to analyse genetic relatedness of leptospiral serogroups. L. harajo-bovis and L. hardjo-prajitno were separated into two distinct groups because they showed very little homology. Our findings support those of Nielsen et al. (1989) because L. hardjo-bovis harboured the repetitive element which, as this work shows, contributes significantly to cross-hybridization. The question arises as to the contribution the repetitive element makes to grouping by cross-hybridization. If all Leptospira serogroups harbouring the repetitive element were clonally derived, these serogroups may have arisen from one progenitor. It is possible that differences in terms of pathogenicity, host range, serology and biochemistry may be attributable to the mutational effects of the repetitive element.

The authors acknowledge the significant culture and DNA preparative work of John Woolley and Jackie Redstone, the helpful discussion with Neil Palmer and the technical advice from Dr R. G. Hewinson.

\section{References}

BERG, D. E. (1980). Control of gene expression by a mobile genetic recombinational switch. Proceedings of the National Academy of Sciences of the United States of America 77, 4880-4884.

Calos, M. P. \& Miller, J. H. (1980). Transposable elements. Cell 20. 579-595.

Chappel, R. J., Millar, B. D., Adler, B., Hill, J., Jeffers, M. J., Jones R. T., McCaughan, C. J., Mead, L. J. \& Silbreck, N. W. (1989). Leptospira interrogans serovar hardjo is not a major cause of bovine abortion in Victoria. Australian Veterinary Journal 66, 330333.

COLE, J. R. (1984). Spirochetes. In Diagnostic Procedures in Veterinary Bacteriology and Mycology, 4th edn, pp. 40-65. Edited by G. R Carter. Springfield, Illinois: Charles C. Thomas Publishing.

Ellis, W. A. (1986). The diagnosis of leptospirosis in farm animals. In The Present State of Leptospirosis Diagnosis and Control, pp. 13-31. Edited by W. A. Ellis \& T. W. A. Little. Dordrecht, The Netherlands: Martinus Nijhoff.

Ellis, W. A., O'Brien, J. J. \& Neill, S. D. (1982). Bovine leptospirosis: microbiological and serological findings in aborted fetuses. Veterinary Record 110, 147-150.

FeinberG, A. P. \& Vogelstein, B. (1983). A technique for radiolabelling DNA restriction endonuclease fragments to high specific activity. Analytical Biochemistry, 132, 6-13.

Hata, K., Yamaguchi, T., Ono, E. \& Yanagawa, R. (1988) Comparative analysis of leptospiral strains ictero number 1 and RGA by restriction endonuclease DNA analysis. Japanese Journal of Veterinary Research, 36, 133-136

Hefron, F. (1983). Tn 3 and its relatives. In Mobile Genetic Elements, pp. 217-262. Edited by S. L. Shapiro. London: Academic Press.

Johnson, R. C. \& FaINE, S. (1984). Leptospiraceae. In Bergey's Manual of Systematic Bacteriology, vol. 1, pp. 62-67. Edited by N. R. Krieg, \& J. G. Holt. Baltimore: Williams \& Wilkins.

KLECKNER, N. (1979). DNA sequence analysis of Tnl0 insertions: origin and role of 9 bp flanking repetitions during TN10 translocation. Cell 16, $711-720$

Lecour, H., Miranda, M., Magro, C., Rocha, A. \& Goncalves, V. (1989). Human leptospirosis - a review of 50 cases. Infection 17, 8 12

Maniatis, T., Fritsch, E. F. \& Sambrook, J. (1982). Molecular Cloning: a Laboratory Manual. Cold Spring Harbor, NY: Cold Spring Harbor Laboratory.

Marshall, R. B., Wilton, B. E. \& Robinson, A. J. (1981). Identification of Leptospira serovars by restriction-endonuclease analysis. Journal of Medical Microbiology 14, 163-166.

Nielsen, J. N., ARmstrong, C. H. \& Nielsen, N. C. (1989). Relationships among selected Leptospira interrogans serogroups as determined by nucleic acid hybridisation. Journal of Clinical Microbiology 27, 2724-2729.

Ohtsubo, H. \& OHtsubo, E. (1977). Repeated DNA sequences in plasmids, phages and chromosomes. In DNA Insertion Elements, Plasmids and Episomes, pp. 49-64. Edited by A. I. Bukhari, J. A. Shapiro \& S. L. Adhya. Cold Spring Harbor, NY: Cold Spring Harbor Laboratory.

Robinson, A. J., Ramadass, P., Lee, A. \& Marshall, R. B. (1982). Differentiation of subtypes within Leptospira interrogans serovars Hardjo, Balcanica and Tarassovi by BRENDA. Journal of Medical Microbiology 15, 331-338.

Saiki, R. K., Scharf, S., Faloona, F., Mullis, K. B., Horn, G. T., ERLICH, H. A. \& ARNHEIM, N. (1985). Enzymatic amplification of $\beta$ globin genomic sequences and restriction site analysis for diagnosis of sickle cell anemia. Science 230, 1350-1354.

Sambrook, J., Fritsch, E. F. \& Maniatis, T. (1989). Molecular Cloning: a Laboratory Manual, 2nd edn. Cold Spring Harbor, NY: Cold Spring Harbor Laboratory.

Silbreck, N. W. \& Davies, W. D. (1989). Restriction endonuclease analysis of Australian isolates of Leptospira interrogans serovar hardjo. Australian Veterinary Journal 66, 183-184.

Terpstra, W. J., Schoone, G. J. \& Ter SchegGeT, J. (1986). Detection of leptospiral DNA by nucleic acid hybridization with ${ }^{32} \mathrm{P}-$ and biotin-labelled probes. Journal of Medical Microbiology 22, 23-28. 
Thiermann, A. B. (1984). Leptospirosis: current development and trends. Journal of the American Veterinary Medical Association 184, 722-725.

Thiermann, A. B., Handsaker, J. W., Foley, J. W. \& Kinscote, B. (1986). Reclassification of leptospiral isolates belonging to serogroups Mini and Sejroe by restriction endonuclease analysis. American Journal of Veterinary Research 47, 61-66.

VAN Eys, G. J. J. M., ZAAl, J. \& Schoone, G. J. (1988). DNA hybridization with hardjobovis-specific recombinant probes as a method for type discrimination of Leptospira interrogans serovar hardjo. Journal of General Microbiology 134, 567-574.
Van Eys, G. J. J. M., Gravenkamp, C., Gerritsen, M. J., Quint, W., Cornelissen, M. T. E., Ter SChegget, J. \& Ter PSTRA, W. J. (1989). Detection of Leptospires in urine by Polymerase Chain Reaction. Journal of Clinical Microbiology 27, 2258-2262.

Zainuddin, Z. \& Dale, J. W. (1989). Polymorphic repetitive DNA sequences in Mycobacterium tuberculosis detected with a gene probe from a Mycobacterium fortuitum plasmid. Journal of General Microbiology 135, 2347-2355.

ZueRner, R. L. \& Bolin, C. A. (1988). Repetitive sequence element cloned from Leptospira interrogans serovar hardjo type hardjo-bovis provides a sensitive diagnostic probe for bovine leptospirosis. Journal of Clinical Microbiology 25, 2236-2238. 